Scientific Journal of October 6 University

ISSN (Print): 2314-8640

ISSN (Electronic): 2356-8119

Published by October 6 University (C) All Rights Reserved

Available online at: http:// sjou.journals.ekb.eg

Original Article
Citation: Helal et al., (2017). Curcumin nanoemulsion a new formulation for an old drug: In vitro and in vivo study . Sci. J. of Oct. 6 Univ. 4 (1), 36-41.

Copyright: ๑ 2017 Helal et al. This is an open-access article distributed under the terms of the Creative Commons Attribution License, which permits unrestricted use, distribution, and reproduction in any medium, provided the original author and source are credited.

\title{
Curcumin nanoemulsion a new formulation for an old drug: In vitro and in vivo study
}

\author{
Helal A. I, EI Baz A. F. and Maksoud A. I.
}

${ }^{1}$ Industrial Biotechnology Department- GEBRI institute- Sadat City University, Egypt.

\section{Received: 13-03-2017/ Revised: 10-04-2017 / Accepted: 20-05-2017}

\begin{abstract}
Curcumin nano emulsion have been tested in vivo and in vitro for its antioxidant and antitumor activity, Cytotoxicity of curcumin nano emulsion have been studied in vitro and found that a concentration of $100 \mathrm{mg} / \mathrm{ml}$ decrease the EAC count by $29.4 \%$. There was a very high significant increase in CAT activity by $135.2 \%$ and very high significant decrease in MDA level, ALT/GPT, AST/GOT and serum creatinine by $49.6 \%, 30.8 \%$, $18.9 \%$ and $43.4 \%$ respectively.
\end{abstract}

Key Words: Antioxidant, antitumor, in MDA level, ALT/GPT, AST/GOT and serum creatinine.

\section{Introduction}

Curcumin is the chief component of the spice turmeric and is derived from the rhizome of the East Indian plant Curcuma longa. Curcuma longa is a member of the Zingiberacae (ginger) family of botanicals and is a perennial plant that is native to Southeast Asia (Wilken et al., 2011).

Turmeric contains a class of compounds known as the curcuminoids, comprised of curcumin, demethoxycurcumin and bisdemethoxycurcumin (Fig.1) (Jurenka, 2009). Curcumin is the principal curcuminoid and comprises approximately $2-5 \%$ of turmeric; it is responsible for the yellow color of the spice as well as the majority of turmeric's therapeutic effects (Chattopadhyay et al., (2004).

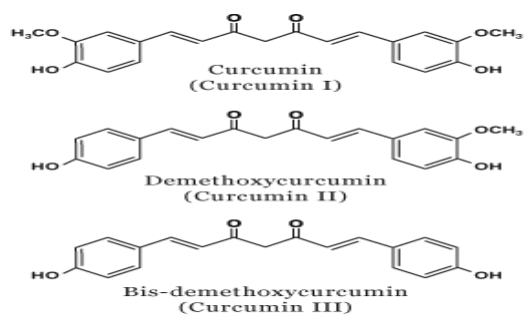

Fig.(1). Structure of Curcuminoids (Aggarwal et al., 2004)
Curcumin displays potent pharmacological effects, by targeting many critical cellular factors, through a diverse array of mechanisms of action (Beevers and Huang, 2011) and it is inexpensive and has been found to be safe in human clinical trials.

The pharmacokinetic, pharmacodynamics, and clinical pharmacological properties of curcumin have been extensively studied over the past six decades These studies have demonstrated that curcumin functions as an antioxidant (Rukkumani et al., 2003), anti-inflammatory (Chainani-Wu, 20003), and anti-atherosclerotic; inhibits scarring, cataract, and gallstone formation; promotes wound healing (Shahed et al., 2001) and muscle regeneration; prevents liver injury and kidney toxicity; and exerts medicinal benefits against psoriasis, diabetes, multiple sclerosis[9], Alzheimer's (Natarajan and Bright, 2002), HIV disease (Lim et al., 2001), septic shock, cardiovascular disease, lung fibrosis (Aggarwal et al., 2006), arthritis, and inflammatory bowel disease (Punithavathi et al., 2000). Recently, curcumin has garnered interest as a potential anticancer agent, for both chemopreventative and chemotherapeutic purposes. Curcumin can effectively inhibit almost every major stage of carcinogenesis, including transformation, initiation, promotion, invasion, angiogenesis, and metastasis (Beevers et al., 2011). 
In spite of its promising therapeutic index, the biological activity of curcumin is severely limited due to its poor bioavailability and hence has not yet been approved as a therapeutic agent. Effective methods to deliver such substances to increase their bioavailability have been a major challenge in current biomedical and food research (Ravichandran, 2013).

It the present study we used the nano emulsion formulation to increase the bioavailability of curcumin and to examine the cytotoxicity and antioxidant activity for the new formula.

\section{Materials and Methods \\ 2.1 Materials}

RPMI1640 (Roswell park memorial institute) medium with L-glutamine (Cambrex, Belgium), Curcumin, Trypan Blue, Bovine serum albumin, Glutaraldehyde 50\% (Sigma, USA). Biochemical kits were purchased from local market, Ehrlich Ascites Carcinoma Cells (EAC) was purchased by the National Cancer Institute (NCI), Cairo University, Egypt, and was maintained by weekly intra-peritoneal transplantation of $2.5 \times 10^{6} / \mathrm{ml}$ cells in female Swiss albino mice.

\subsection{Experimental animals}

Forty five female Swiss albino mice, 12-14 weeks old age and weighing about 20-25 g (obtained from Laboratory Animals Research Center, Faculty of Veterinary Medicine, Zagazig University, Egypt) were used throughout this study. The animals were housed in steel mesh cages (10-15 per cage), in animal house, Faculty of science, Zagazig University, Egypt and allowed to become acclimatized to laboratory conditions for one week before the experiment also water was supplied $a d$ Libitum

\subsection{Curcumin nano-emulsion preparation} (Jithan et al., 2011).

$100 \mathrm{mg}$ bovine serum albumin(BSA) is dissolved in $12 \mathrm{ml}$ distilled water; dissolve the curcumin 24 $\mathrm{mg}$ in $24 \mathrm{ml}$ ethanol then add drop wise the ethanolic solution on the BSA solution under stirring (500 rpm); then add $3 \mathrm{ml} 11 \%$ glutaraldehyde and leave on stirring overnight.

\subsection{Determination of Curcumin nanoemulsion} size Dynamic Light Scattering (DLS) technique Analysis was performed (scattering angle $=90^{\circ}$, laser wavelength $=632.8 \mathrm{~nm}$ ) on a 256 channel Photocor-FC (Photocor Inc., USA) operated in the multi-tau mode (logarithmically spaced channels). Few milliliters of the sample was drawn into borosilicate cylindrical cell (volume $=5 \mathrm{~mL}$ ) and DLS experiment was performed. The data was analyzed both in the CONTIN regularization and discrete distribution modes (multi-exponential).
2.5 Cytotoxicity assay against Ehrlich Ascites Carcinoma (EAC) cells by trypan blue exclusion method:

This test was done according to Ribeiro Ribeiro et al., (2006), briefly Ascites fluid was withdrawn under aseptic conditions from the peritoneal cavity of tumor bearing mice by needle aspiration after 7 days of EAC cells inoculation. To adjust the number of EAC cells $/ \mathrm{ml}$, tumor cells obtained was diluted several times with normal saline. EAC viable cells were counted by trypan blue exclusion method where, $10 \mu \mathrm{l}$ trypan blue $(0.05 \%)$ was mixed with $10 \mu \mathrm{l}$ of the cell suspensions. Within 5 minutes, the mixture was spread onto haemocytometer, covered with a cover slip and then cells were examined under microscope. Dead cells are blue stained but viable cells are not.

\subsection{Determination of Serum Lipid Peroxide (Malodialdehyde)}

Malodialdehyde (MDA) was determined by using Biodiagnostic kit according to the method of Satoh et al., (1978). Briefly $0.2 \mathrm{ml}$ of serum mixed well with $1.0 \mathrm{ml}$ chromogen and heated in a water bath for 30 minutes then get reading using UV-200-Rs spectrophotometer (Lw scientific, Umedic, Germany) at $534 \mathrm{~nm}$

\subsection{Assessment of catalase enzyme activity (Aebi, 1984)}

This test was done according to Schumann and Klauke, 2003, briefly $0.05 \mathrm{ml}$ from serum sample mixed well with $0.05 \mathrm{ml}$ of phosphate Buffer 100 $\mathrm{mM} / \mathrm{l}, 0.1 \mathrm{H}_{2} \mathrm{O}_{2} 500 \mathrm{mM} / \mathrm{l}$ then incubate tubes for exactly one minute at $25 \mathrm{C}$ then add $0.2 \mathrm{ml}$ Chromogen inhibitor and $0.5 \mathrm{ml}$ 4Aminoantipyrine preservative $2 \mathrm{mM} / \mathrm{l}$ and Peroxidase > 2000/1. All tubes were Incubated 10 min at $37^{\circ} \mathrm{C}$, read sample against sample blank and standard against standard blank at $510 \mathrm{~nm}$ using ECO 308 BIOCHEMISTRY ANALYSER. Color is stable for one hour.

\subsection{Determination of plasma Alanine Amino- transferase (ALT/ GPT)}

This test was done according to Karmen et al., 1955 , briefly At $37{ }^{\circ} \mathrm{C}$ Pipette into cuvettes $100 \mu$ of sample to $1000 \mu$ of working solution which composed of TRIS buffer (PH 7.5) $150 \mathrm{mmol} / \mathrm{l}$, Lalanine $750 \mathrm{mmol} / \mathrm{l}, \mathrm{LDH}>1.2 \mathrm{KU} / \mathrm{l}$,2oxoglutarate $90 \mathrm{mmol} / \mathrm{l}$ and NADH $0.9 \mathrm{mmol} / \mathrm{l}$, Mix, read the absorbance after 1 minute and at the same time start the stop watch, read the absorbance again exactly after 1.2 and 3 minutes.

\subsection{Determination of plasma Aspartate Amin- otransferase (AST/ GOT)}

This test was done according to Karmen et al., 1955, briefly At $37{ }^{\circ} \mathrm{C}$ Pipette into cuvettes $100 \mu$ of sample to $1000 \mu \mathrm{l}$ of working solution which composed of -TRIS buffer (PH 7.8) 
mmol/l]; L-aspartate $\quad[300 \mathrm{mmol} / \mathrm{l}] ; \mathrm{LDH} \quad$ [> 0.9 $\mathrm{KU} / \mathrm{l}]$; and MDA [>0.6 KU/l] Substrates:2-oxoglutarate $[60 \mathrm{mmol} / \mathrm{l}]$ and $\mathrm{NADH}[0.9 \mathrm{mmol} / \mathrm{l}]$ and, Mix, read the absorbance after 1 minute and at the same time start the stop watch, read the absorbance again exactly after 1.2 and 3 minutes.

\subsection{Determination of Serum Creatinine}

Add $0.5 \mathrm{ml}$ of Picric acid (17.5 mmol/ $\mathrm{L})$ in standard and test tubes. Add $0.5 \mathrm{ml}$ of Sodium hydroxide $(0.29 \mathrm{~mol} / \mathrm{L})$ in standard and test tubes. Add $100 \mu \mathrm{l}$ of Creatinine aqueous primary standard ( $2 \mathrm{mg} / \mathrm{dl}$ ) in standard tube. Add $100 \mu \mathrm{l}$ of sample (plasma) in test tube. Mix and start stopwatch. Read the absorbance (A1) after 30 seconds and after 120 seconds (A2) of the sample addition.

\subsection{Statistical Analysis}

All statistical analyses were done by a statistical for social science package "SPSS" 14.0 for Microsoft Windows, SPSS Inc. (Levesque, 2007) and considered statistically significant at a two-sided $\mathrm{P}$ $<0.05$.

Numerical data were expressed as mean \pm SD. The levels of markers were analyzed by ANOVA. The correlations between serum biochemical data in different studied groups were evaluated by Person's correlation coefficient, to quantify the relationship between the studied parameters. $\mathrm{P}$ value $<0.01$ was considered significant.

\section{Results}

\subsection{Determination of Curcumin nano emulsion droplet size by DLS}

Fig. 1 presents a typical Dynamic light scattering (DLS) image of Curcumin nanoemulsion. The analysis of the size distribution results in an average diameter of $629.7 \mathrm{~nm}$.

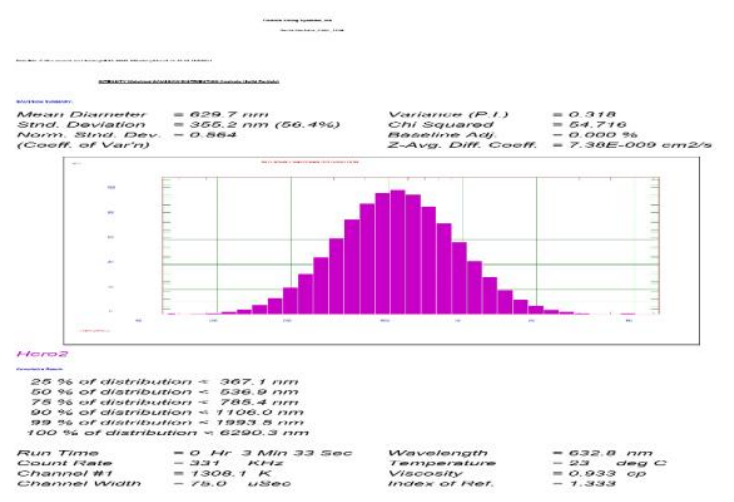

Fig 1 DLS image of curcumin nanoparticles

3.2 Cytotoxicity assay against Ehrlich Ascites Carcinoma (EAC) cells by trypan blue exclusion method
Fig (2) summarize the data of Curcumin nanoemulsion cytotoxicity against EAC cells after 1 hour of incubation. The data were expressed as surviving percent compared with untreated control cells. Treatment of EAC cells with Curcumin nanoemulsion at increasing concentrations (10-200 $\mathrm{mg} / \mathrm{ml}$ ) for one hour showed increase in cytotoxicity of EAC cells with the increase in

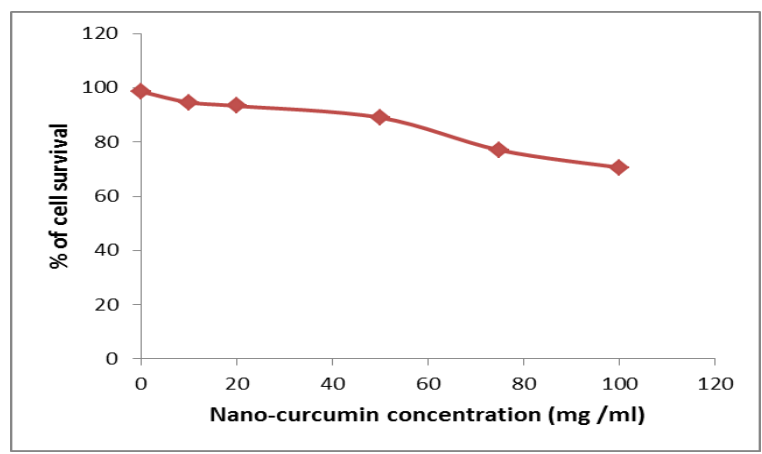

concentration.

Fig (2): Cytotoxicity of Curcumin nano emulsion Ehrlich Ascites Carcinoma (EAC) cells.

\subsection{Determination of Serum Lipid Peroxide (Malodialdehyde)}

Data obtained from Fig (3) Summarizes the effect of Curcumin nano emulsion on the MDA level in mice studied group. The mean of MDA levels were a very highly significant increase $(p<0.001)$ to $42.10 \pm 2.61(\mathrm{nmol} / \mathrm{ml})$ in the positive control group compared to the negative control group 11.49 $\pm 0.83(\mathrm{nmol} / \mathrm{ml})$. Meanwhile, the mean MDA levels showed a very highly significant decrease to $21.21 \pm 1.67(\mathrm{nmol} / \mathrm{ml})$ by $49.6 \% \quad(\mathrm{p}<0.001)$ in curcumin nano emulsion compared to the positive control group.

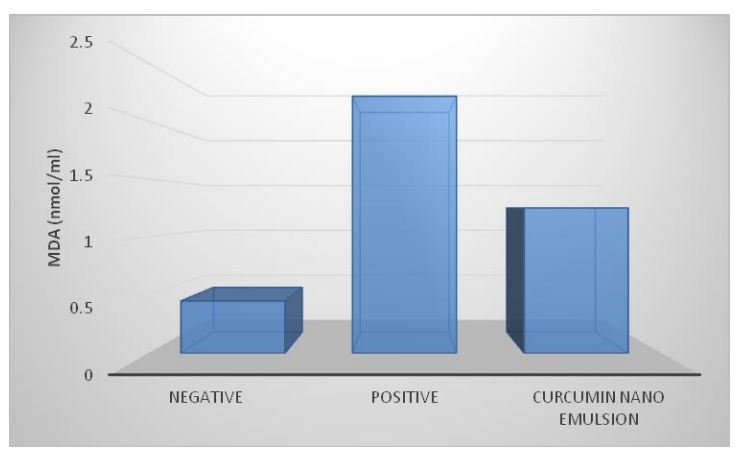

Fig 3: Effect of Curcumin nano emulsion MDA level $(\mathrm{nmol} / \mathrm{ml})$ in mice studied groups.

3.4 Assessment of catalase enzyme activity (CAT) The effect of curcumin nano emulsion on the Catalase activity in mice studied group is illustrated in Fig. (4). the mean of Catalase activities were a very highly significant decrease $(\mathrm{p}<0.001)$ to $152.87 \pm 10.32(\mathrm{U} / \mathrm{L})$ in the positive control group as compared to the negative control group $237.69 \pm$ 
15.22 (U/L). While, the mean Catalase activities showed a very highly significant increase to 359.60 \pm 17.33 (U/L) by $135.2 \%$, $(\mathrm{p}<0.001)$ in curcumin nano emulsion compared to the positive control group.

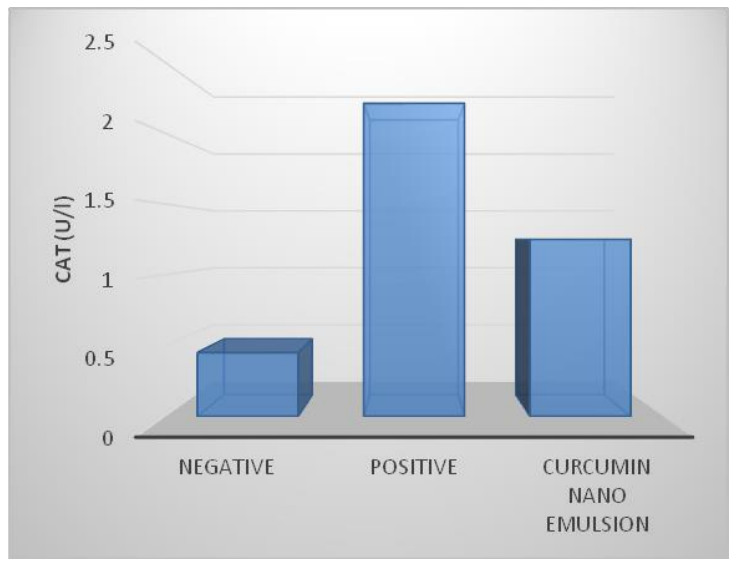

Fig. (4) Effect of Curcumin nanoemulsion on the Catalase activity (U/L) in mice studied groups.

\subsection{Determination of plasma Alanine Amino- transferase (ALT/ GPT)}

Data obtained from Fig. (5) Summarizes the effect of Curcumin nano emulsion on the plasma ALT activity (U/L) in mice studied groups. ALT activity revealed a very highly significant increase $(\mathrm{p}<$ $0.001) 180.92 \pm 18.09(\mathrm{U} / \mathrm{L})$ in positive control group as compared to negative control group 49.40 \pm 8.3 . While, ALT activity (U/L) showed a very highly significant decrease to $125.13 \pm 9.24$ by $30.8 \%$, $(\mathrm{p}<0.001)$ in Curcumin nano emulsion compared to the positive control group.

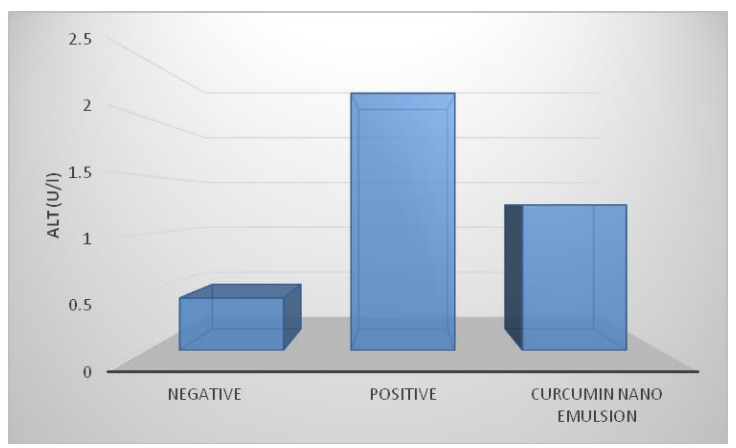

Fig. (5) Effect of Curcumin nano emulsion on the plasma ALT activity (U/L) in mice studied groups.

\subsection{Determination of plasma Aspartate Amino- transferase (AST/ GOT)}

Data obtained from Fig. (6) Summarizes the effect of Curcumin nano emulsion on the plasma AST activity (U/L) in mice studied groups. AST activity $(\mathrm{U} / \mathrm{L})$ revealed a very highly significant increase $(\mathrm{p}<0.001)$ to $234.79 \pm 15.44 .1$ (U/L) in positive control group as compared to negative control group $82.60 \pm 3.09$ (U/L). But, AST activity (U/L) showed a very highly significant decrease to $190.44 \pm 7.62$, (U/L) by $18.9 \%, \quad(\mathrm{p}<0.001)$ in Curcumin nano emulsion compared to the positive control group.

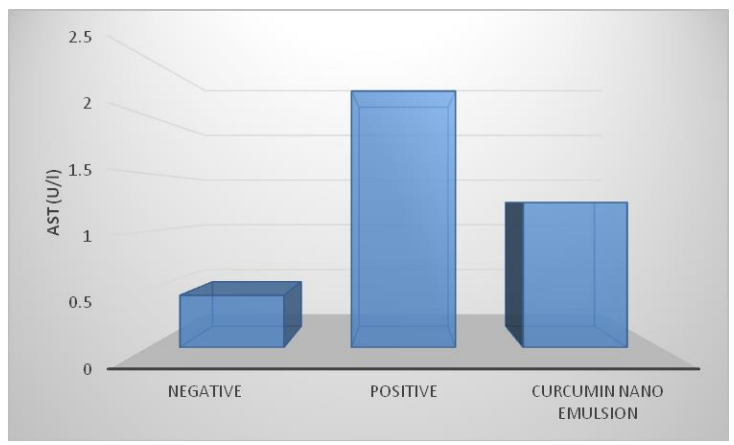

Fig. (6) Effect of Curcumin nano emulsion on the plasma AST activity (U/L) in mice studied groups.

\subsection{Determination of Serum Creatinine}

Fig. (7) Summarize the effect of Curcumin nano emulsion on the Creatinine concentration in mice studied groups. The resulted data revealed a very highly significant increase in the Creatinine concentration $(\mathrm{p}<0.001)$ to $2.21 \pm 0.49(\mathrm{mg} / \mathrm{dl})$ in positive control group compared to negative control group $0.45 \pm 0.13(\mathrm{mg} / \mathrm{dl})$. Meanwhile, it revealed a very highly significant decrease to 1.25 \pm 0.18 (mg/dl) by $43.4 \%$, $(\mathrm{p}<0.001)$, in Curcumin nano emulsion compared to the positive control group.

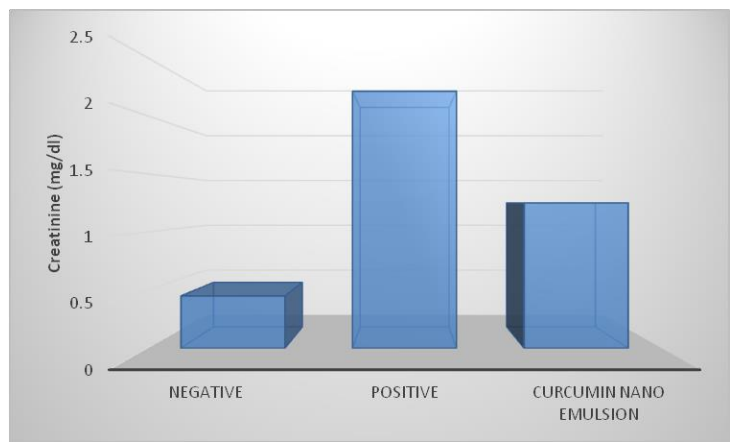

Fig. (7) Effect of Curcumin nano emulsion on the blood Creatinine_concentration $(\mathrm{mg} / \mathrm{dl})$ in mice studied groups.

\section{4- Discussion}

In the present work, in vitro cytotoxicity screening of the compounds under investigation was performed on EAC cells by trypan blue exclusion method.

EAC cells is originated from breast cancer which was modified to be grown in female Swiss albino mice and maintained by intraperitoneal inoculation of carcinoma cells in the mice (Gupta et al., 2004). The major mechanism by which curcumin induces cytotoxicity in tumor cells is induction of 
apoptosis. Curcumin suppresses the growth of several tumor cell lines, including drug-resistant lines (Mukhopadhyay et al., 2002).

The suppression of cell proliferation by curcumin usually occurs through its effects on the cell cycle. Depending on the cell type, the inhibition of cell proliferation at different phases of the cell cycle has been reported. Inhibition of cell proliferation could also be mediated through suppression of ornithine decarboxylase (ODC).

Besides suppression of proliferation, curcumin also induces apoptosis in a wide variety of cells. The mechanism of apoptosis could be either mitochondria-dependent or mitochondria-independent. Normally, cytokines that mediate their signaling through the death receptors induce apoptosis via mitochondria-independent mech-anism.

Depending on the cell type, curcumin induces apoptosis through both mitochondria-dependent as well as mitochondria-independent mechanisms. In most cells curcumin sequentially induces activation of caspase-8, cleavage of BID, loss of mitochondrial membrane potential, opening of transition pores, release of cytochrome $\mathrm{C}$, caspase- 9 activation, caspase-3 activation and cleavage of PARP and inhibitor of caspase-activated deoxyribonuclease (ICAD), thus leading to DNA fragmentation and apoptosis . On treatment of cells with curcumin, cell shrinkage, chromatin conde-nsation, translocation of the AIF to the nucleus, nuclear disintegration and large scale DNA chromatolysis has also been reported.

Down-regulation of anti-apoptotic protein (bcl-2 and bcl-xl) is another potential mechanism by which curcumin could induce apoptosis in cells. Another potential mechanism through which curcumin could induce apoptosis is through the alteration of the redox status of the cells. Curcumin has been shown to induce ROI and alter cellular GSH levels. In contrast to all these studies, there is a recent report that indicates that curcumin could be inhibitory to chemotherapy -induced apoptosis mediated through the suppression of chemotherapy-induced free radical production. Inhibition of PTK and PKC could also contribute to the ability of curcumin to induce apoptosis. From these studies it is clear that curcumin inhibits cell growth and induces apoptosis of various tumor cells through a mechanism similar to that of most chemotherapeutic agents (Aggarwal et al., 2003).

As nanoparticles have unique features which exhibit novel properties different to those of both isolated atoms and bulk material (Albrecht et al., 2006). Due to their very small size, the surface modified nanoparticles conjugated with therapeutic drugs can penetrate the tumors with a high degree of specificity (Albrecht, 2006). So, we use in our research curcumin in nano-form

Implantation of Ehrlich carcinoma tumor into female Swiss albino mice has been proved to induce significant deleterious changes in antioxidant status. The results revealed a very highly significant increase in lipid peroxidation level and a very highly significant decrease in SOD activity and CAT activity in the blood of Ehrlich carcinoma bearing mice.

The antioxidant mechanism of curcumin may include one or more of the following interactions as mentioned by (Cuenca, 2006) (1)Scavenging or neutralizing of free radicals as hydroxyl radical $\left(\mathrm{OH}^{\circ}\right)$ and superoxide radical anion $\left(\mathrm{O}_{2}{ }^{-}\right)$, (2) interacting with oxidative cascade and preventing its outcome, (3) quenching of singlet oxygen, nitrogen dioxide and nitric oxide (NO), and making them less available for oxidative reaction, (4) inhibition of oxidative enzymes like cytochrome P450 and (5) chelating and disarming oxidative properties of metal ions such as iron.

In general, phenolic compounds can act as free radical scavengers by virtue of their hydrogen donating ability, forming aryloxyl (phenoxy) radicals. It has been proposed that hydroxyl and hydroperoxy radicals initiate $\mathrm{H}^{+}$abstraction from a free phenolic substrate to form phenoxy radical that can rearrange to quinonemethide radical inter-mediate which is excreted via bile.

The effect of ROS production, as a result of tumor growth, on other organs in the body can be explained as follows: ROS cause activation in NF$\kappa \mathrm{B}$ and phosphorylation of its inhibitor (I $\mathrm{B}$ ). Thus, they enable $\mathrm{NF}-\kappa \mathrm{B}$ to translocate to the cell nucleus in which it binds to DNA and regulates the transcription of various target genes (i.e., inducible nitric oxide synthase, cyclooxygenase II, cytokines, etc.), which contribute to cell damage Cytokines, TNF- $\alpha$ and interleukins, either produced from tumor cells themselves or ROS formed during tumor growth have cytotoxic properties that cause liver and kidney injury [29].

\section{Conclusion}

As demonstrated from the above results curcumin nano emulsion is a promising therapeutic formula against tumors and it increase the bioavailability of curcumin in the mice groups. 
$\underline{\text { References }}$

Aebi H. (1984): Catalase in vitro, Methods Enzymol 6:105:121. Aggarwal B.B., Indra D.B., Haruyo I., Kwang S.A., Gautam S., Santosh K.S., Chitra N., Navindra S., and Shishir S. (2006): Curcumin — Biological and Medicinal Properties .7034_book.fm Page 300.

Aggarwal B.B., Kumar A. and Bharti A.C. (2003): Anticancer potential of curcumin: preclinical and clinical studies. Anticancer Res. 23:363-398.

Aggarwal B.B., Kumar A., Aggarwal M.S., and Shishodia S., (2005): Curcumin Derived from Turmeric (Curcuma longa): a Spice for All Seasons. Phytopharmaceuticals in Cancer Chemoprevention, 349-387.

Aggarwal B.B., Sundaram C., Malani N. and Ichikawa H. (2007): Curcumin: The Indian solid gold. Adv Exp Med Biol. 595:175.

Albrecht, M. A.; Evans, C. W.; Raston, C. L. (2006): Green chemistry and the health implications of nanoparticles. J.Green Chem. 8:417-432.

Beevers C. S. and Huang S. (2011): Pharmacological and clinical properties of curcumin. Botanics: Targets and Therapy .1: 5-18

Beevers C. S. and Huang S. (2011): Pharmacological and clinical properties of curcumin. Botanics: Targets and Therapy .1: 5-18

Chainani-Wu, N. (2003): Safety and antiinflammatory activity of curcumin: a component of turmeric (Curcuma longa). J Altern. Complement Med. 9, 161-168.

Chattopadhyay I., Biswas K., Bandyopadhyay U. and Banerjee R.K. (2004): Turmeric and curcuminBiological actions and medicinal applications. Curr Sci, 87:44-50.

Cuenca A.G., Jiang H.B., Hochwald S.N., Delano M, Cance W.G., and Grobmyer S.R. (2006): Emerging implications of nanotechnology on cancer diagnostics and therapeutics. Cancer.;107:459-466.

Gupta A., Mazumder U.K., Kumar R.S. \& Kumar T.S.; (2004): Anti-tumor activity and anti-oxident role of Bauhinia racemosa against Ehrlich ascites carcinoma in Swiss albino mice. Act. Pharm. Sin. 25(8): 1070-1076.

Jithan A.V., Madhavi M., Madhavi K., Prabhakar K (2011): Preparation and characterization of albumin nanoparticles encapsulating curcumin intended for the treatment of breast cancer, Int. J. of Pharmac. Invest. (1) $119-125$

Jurenka J.S.(2009): Anti-inflammatory properties of curcumin, a major constituent of Curcima longa: A review of preclinical and clinical research. Altern Med Rev. 14:141-153

Karmen A., Wroblewski F. and, LaDue J.S. (1955): Transaminase activity in human blood. J. Clin. Invest 34:12631.

Lehman V., Freudenberg M.A. and Galanos C. (1987): Lethal toxicity of lipopolysaccharide and tumor necrosis factor in normal and D-galactosamine treated mice. J Exp Med. 165:657-663.

Levesque R. SPSS., (2007): Programming and Data Management: A Guide for SPSS and SAS Users, Fourth Edition, SPSS Inc., Chicago Ill.
Lim G.P., Chu T., Yang F., Beech W., Frautschy S.A. and Cole G.M. (2001): The curry spice curcumin reduces oxidative damage and amyloidpathology in an Alzheimer transgenic mouse. J Neurosci $21: 8370-8377$

Mukhopadhyay A., Banerjee S., Stafford L.J., Xia C., Liu M., and Aggarwal B.B., (2002): Curcumin-induced suppression of cell proliferation correlates with down-regulation of cyclin D1 expression and CDK4-mediated retinoblastoma protein phosphorylation. Oncogene; 21: 8852-8862.

Natarajan C., and Bright J.J. (2002): Curcumin inhibits experimental allergicencephalomyelitis by blocking IL-12 signaling through Januskinase-STAT pathway in T- lymphocytes. J Immunol 168:6506-6513

Punithavathi D., Venkatesan N،. and Babu M.; (2000): Curcumin inhibition of bleomycin induced pulmonary fibrosis in rats. $\mathrm{Br} . J$. Pharmacol.131, 169-172.

Ravichandran R.(2013): Pharmacokinetic Study of Nanoparticulate Curcumin:Oral Formulation for Enhanced Bioavailability Journal of Biomaterials and Nanobiotechnology,. 4, 291-299

Ribeiro Ribeiro, D.A.; Marques, M.E. and Salvadori, D.M. (2006): In vitro cytotoxic and non-genotoxic effects of Gutta-Percha solvents on mouse lymphoma cells by single cell gel (comet) assay. Braz Dent J., 17(3):228-232.

Rukkumani M.S., and Balasubashini V.P.M.; (2003): Protective effects of curcumin and photo-irradiated curcumin on circulatory lipids and lipidperoxidation products in alcohol and polyunsaturated fatty acid-inducedtoxicity. Phytother.Res. 17: 925-929.

Rukkumani M.S., and Balasubashini V.P.M.; (2003): Protective effects of curcumin and photo-irradiated curcumin on circulatory lipids and lipidperoxidation products in alcohol and polyunsaturated fatty acid-inducedtoxicity. Phytother.Res. 17: 925-929.

Satoh K., (1978): Serum Lipid Peroxide in cerebrovascular disorders determined by a new colorimetric method. Clinica Chimica Acta 90:37-43.

Schumann G., and Klauke R., (2003): New IFCC reference procedures for the determination of catalytic activity concentrations of five enzymes in serum: preliminary upper reference limits obtained in hospitalized subjects. Clin. Chim. Acta., 327 (1-2): 6979.

Shahed A.R., Jones E., and Shoskes D.; (2001): Quercetin and curcumin up-regulate antioxidant gene expression in rat kidney after ureteral obstruction or ischemia/reperfusion injury. Transplant Proc 33(6), 2988.

Wilken R., Veena M.S., Wang M.B. and Srivatsan E.S.(2011): Curcumin: A review of anti-cancer properties and therapeutic activity in head and neck squamous cell carcinoma. Molecular Cancer., 10:12 